\title{
Heme Oxygenase-1 Determines the Differential Response of Breast Cancer and Normal Cells to Piperlongumine
}

\author{
Ha-Na Lee', Hyeon-Ok Jin', Jin-Ah Park', Jin-Hee Kim', Ji-Young Kim', BoRa Kim', Wonki Kim², Sung-Eun

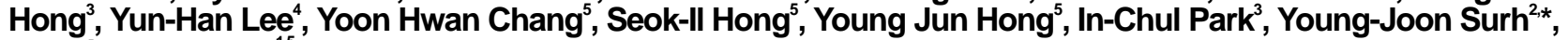 \\ and Jin Kyung Lee $e^{1,5, *}$
}

Piperlongumine, a natural alkaloid isolated from the long pepper, selectively increases reactive oxygen species production and apoptotic cell death in cancer cells but not in normal cells. However, the molecular mechanism underlying piperlongumine-induced selective killing of cancer cells remains unclear. In the present study, we observed that human breast cancer MCF-7 cells are sensitive to piperlongumine-induced apoptosis relative to human MCF$10 A$ breast epithelial cells. Interestingly, this opposing effect of piperlongumine appears to be mediated by heme oxygenase-1 (HO-1). Piperlongumine upregulated HO-1 expression through the activation of nuclear factorerythroid-2-related factor-2 (Nrf2) signaling in both MCF-7 and MCF-10A cells. However, knockdown of HO-1 expression and pharmacological inhibition of its activity abolished the ability of piperlongumine to induce apoptosis in MCF-7 cells, whereas those promoted apoptosis in MCF$10 A$ cells, indicating that $\mathrm{HO}-1$ has anti-tumor functions in cancer cells but cytoprotective functions in normal cells. Moreover, it was found that piperlongumine-induced Nrf2 activation, HO-1 expression and cancer cell apoptosis are not dependent on the generation of reactive oxygen species. Instead, piperlongumine, which bears electrophilic $\alpha, \beta$-unsaturated carbonyl groups, appears to inactivate Kelch-like ECH-associated protein-1 (Keap1) through thiol modification, thereby activating the Nrf2/HO-1 pathway and subsequently upregulating HO-1 expression, which

${ }^{1}$ KIRAMS Radiation Biobank, Korea Institute of Radiological and Medical Sciences, Seoul 139-709, Korea, ${ }^{2}$ College of Pharmacy, Seoul National University, Seoul 151-742, Korea, ${ }^{3}$ Division of Radiation Cancer Research, Korea Institute of Radiological and Medical Sciences, Seoul 139-709, Korea, ${ }^{4}$ Department of Radiation Oncology, College of Medicine, Yonsei University, Seoul 120-752, Korea, ${ }^{5}$ Department of Laboratory Medicine, Korea Cancer Center Hospital, Korea Institute of Radiological and Medical Sciences, Seoul 139-709, Korea

*Correspondence: jklee@ kirams.re.kr (JKL); surh@ plaza.snu.ac.kr (YJS)

Received 2 September, 2014; revised 9 December, 2014; accepted 22 December, 2014; published online 20 March, 2015

Keywords: apoptosis, breast cancer, $\mathrm{HO}-1, \mathrm{Nrf2}$, piperlongumine accounts for piperlongumine-induced apoptosis in cancer cells. Taken together, these findings suggest that direct interaction of piperlongumine with Keap1 leads to the upregulation of Nrf2-mediated HO-1 expression, and HO-1 determines the differential response of breast normal cells and cancer cells to piperlongumine.

\section{INTRODUCTION}

Phytochemicals have been emerging as the most dependable resource of therapeutic agents for inflammatory disorders and cancers. Piperlongumine, a natural alkaloid isolated from the long pepper (Piper longum L.), is known to have insecticidal, bactericidal (Yang et al., 2002), anti-diabetic effects (Rao et al., 2012), and anti-atherosclerotic effects (Son et al., 2012) as well as cytotoxic and anti-tumor effects (Raj et al., 2011). It has been reported that piperlongumine can selectively kill various cancer cells and transformed cells overexpressing oncogenes (e.g., ERBB2 and/or HRAS), but not normal cells (Raj et al., 2011). Moreover, this molecule dramatically suppressed tumor growth, angiogenesis and metastasis in bladder, breast and lung tumor tissues without affecting normal tissues in tumor xenograft mouse models (Raj et al., 2011). The differential response of cancer cells and normal cells to piperlongumine appears to be mediated by targeting the higher dependency of cancer cells on the oxidative stressresponse pathway relative to normal cells. Piperlongumine enhances the accumulation of reactive oxygen species (ROS) in cancer cells by interfering with redox and ROS homeostatic regulators such as glutathione S-transferase pi 1 (GSTP1) and carbonyl reductase 1 (CBR1) (Raj et al., 2011). It has also been demonstrated that piperlongumine-induced ROS generation is dependent on the activation of mitogen activated protein kinases (MAPKs) including c-Jun-N-terminal kinase (JNK) and p38 (Liu et al., 2013).

Heme oxygenase-1 (HO-1), also known as heat shock protein 32 (HSP32), is a representative redox-regulated protein involved in cellular antioxidant and cytoprotective mechanisms (Bauer and Bauer, 2002). Under normal physiological conditions, induction of $\mathrm{HO}-1$ expression is considered as an important adaptive survival response in stressed cells challenged with oxidative stress, UV irradiation, pro-inflammatory cytokines, cisplatin and 6-hydroxydopamine (Bae et al., 2013; Ewing et al., 2005; Kim et al., 2006; Lin et al., 2005; 2007). In addition to its

elSSN: 0219-1032

(C) The Korean Society for Molecular and Cellular Biology. All rights reserved.

(c) This is an open-access article distributed under the terms of the Creative Commons Attribution-NonCommercial-ShareAlike 3.0 Unported License. To view a copy of this license, visit http://creativecommons.org/licenses/by-nc-sa/3.0/. 
cytoprotective effect, HO-1 has been reported to induce apoptosis and suppress proliferation and invasion in breast cancer cells (Hill et al., 2005; Lee et al., 2014; Lin et al., 2008). In hepatocellular carcinomas, cell migration and xenograft tumor growth were significantly inhibited by $\mathrm{HO}-1$ overexpression (Zou et al., 2011). Furthermore, several studies have revealed that chemopreventive agents, including sulforaphane, suppress tumorigenesis through induction of $\mathrm{HO}-1$ expression (Cornblatt et al., 2007; Keum et al., 2006), indicative of the antitumor activity of $\mathrm{HO}-1$.

$\mathrm{HO}-1$ is well-known to be regulated by nuclear factor-erythroid2-related factor 2 (Nrf2), a stress-responsive transcription factor. $\mathrm{Nrf} 2$ binds to antioxidant response element (ARE), a cisregulatory DNA sequence located in the promoter of target genes encoding phase 2 detoxifying enzymes and cytoprotective proteins (Itoh et al., 1997). Under physiological conditions, Nrf2 is bound to the Kelch-like ECH-associated protein 1 (Keap1) in the cytoplasm and undergoes proteasomal degradation by the Keap1-Cul3 E3 ubiquitin ligase complex (Alam et al., 1999). In response to oxidative or electrophilic stress, however, Nrf2 dissociates from Keap1, thereby escaping from proteasomal degradation and translocating into the nucleus where it heterodimerizes with other transcription factors such as small Maf and binds to ARE (Kensler et al., 2007). Several studies have demonstrated that the dissociation of Nrf2 from Keap1 is most likely regulated by alterations in Keap1 structure. Oxidative stress or electrophiles can cause oxidation or covalent modification of cysteine residues within Keap1, thereby activating Nrf2 signaling (Kim et al., 2014; Kobayashi et al., 2009; Yamamoto et al., 2008).

Numerous chemopreventive phytochemicals which contain an $\alpha, \beta$-unsaturated carbonyl moiety activate Nrf2 signaling and subsequently induce the expression of cytoprotective enzymes including HO-1 (Zhang et al., 2004). Piperlongumine also bears two electrophilic $\alpha, \beta$-unsaturated carbonyl groups, and hence is expected to upregulate the expression of $\mathrm{HO}-1$ through activation of Nrf2 signaling. In this study, we explored the piperlongumineinduced selective killing of cancer cells with special focus on $\mathrm{HO}$ 1. Furthermore, we demonstrated the possible mechanism involved in piperlongumine-mediated Nrf2 activation and $\mathrm{HO}-1$ induction.

\section{MATERIALS AND METHODS}

\section{Materials}

Piperlongumine was purchased from Biovision (USA). Dulbecco's Modified Eagle Medium (DMEM) was obtained from Welgene (Korea). Dulbecco's modified Eagle's medium (DMEM)/ Ham's nutrient mixture F-12, horse serum and fetal bovine serum (FBS) were produced from Gibco BRL (USA). The primary antibody against HO-1 was purchased from Stressgen (Canada), and an antibody against cleaved poly (ADP-ribose) polymerase (PARP) was obtained from Cell Signaling (USA). Primary antibodies against Nrf2, lamin B and $\alpha$-tubulin were purchased from Santa Cruz Biotechnology (USA). The anti-rabbit, anti-mouse and anti-goat horseradish peroxidase-conjugated secondary antibodies were obtained from Zymed Laboratories (USA). Zinc protoporphyrin (ZnPP) was the product of Alexis Corporation (Lausen, Switzerland). N-Acetyl-L-cysteine (NAC), ( \pm )6-hydroxy-2,5,7,8-tetramethylchromane-2-carboxylic acid (trolox) and dithiothreitol (DTT) were supplied from Sigma Chemical Co. (USA).

\section{Cell culture}

MCF-7 and MCF-10A cells were purchased from American Type Culture Collection (USA). MCF-7 cells were cultured in
DMEM with $10 \%$ FBS, $100 \mu \mathrm{g} / \mathrm{ml}$ streptomycin and $100 \mathrm{U} / \mathrm{ml}$ penicillin, and MCF-10A cells were maintained in DMEM/F12 medium supplemented with $10 \mu \mathrm{g} / \mathrm{ml}$ insulin (bovine), 100 $\mathrm{ng} / \mathrm{ml}$ cholera toxin, $0.5 \mu \mathrm{g} / \mathrm{ml}$ hydrocortisone, $20 \mathrm{ng} / \mathrm{ml}$ recombinant human epidermal growth factor, $2 \mathrm{mM}$ L-glutamine, 100 $\mu \mathrm{g} / \mathrm{ml}$ penicillin/streptomycin/fungi zone mixture and $5 \%$ heatinactivated horse serum in humidified $5 \% \mathrm{CO}_{2}$ at $37^{\circ} \mathrm{C}$.

\section{MTT assay}

Cell viability was assessed using 3-(4,5-dimethylthiazol-2-yl)2,5-diphenyltetrazolium bromide (MTT, Sigma). In brief, MCF$10 \mathrm{~A}$ and MCF-7 cells were plated at a density of $3 \times 10^{4}$ cells in 48 -well plates and cultured at $37^{\circ} \mathrm{C}$ for $24 \mathrm{~h}$. The medium was then replaced with fresh medium containing piperlongumine at various concentrations $(0,1$ and $5 \mu \mathrm{M})$. After incubation for 24 $\mathrm{h}$, the supernatant was removed and cells were treated with MTT solution $(0.25 \mathrm{mg} / \mathrm{ml})$ for $2 \mathrm{~h}$ at $37^{\circ} \mathrm{C}$. The formazan crystals that had formed in viable cells were measured at $570 \mathrm{~nm}$ using a microplate reader. The results are expressed as the percentage of $\mathrm{MTT}$ reduction, assuming that the absorbance of control cells was $100 \%$.

\section{Flow cytometry analysis}

Apoptotic cell death was measured by annexin-V-FITC staining according to the manufacturer's instructions. Cells were treated with piperlongumine for $36 \mathrm{~h}$ and collected. Washed cell pellets were resuspended in $100 \mu$ of annexin V binding buffer (Invitrogen, USA) and incubated with $5 \mu \mathrm{l}$ of FITC-conjugated annexin $\mathrm{V}$ (Invitrogen) and $1 \mu \mathrm{l}$ of propidium iodide (Invitrogen) for $15 \mathrm{~min}$ in the dark. Annexin V binding buffer $(400 \mu \mathrm{l})$ was then added, and the cells were analyzed by flow cytometry.

\section{Cell cycle analysis}

MCF-10A and MCF-7 cells were treated with $5 \mu \mathrm{M}$ of piperlongumine for $24 \mathrm{~h}$ and harvested. After washing with icecold PBS, the cells were fixed using $500 \mu$ of ice-cold $70 \%$ ethanol, and incubated overnight at $4^{\circ} \mathrm{C}$. Cells were washed twice with $500 \mu \mathrm{l}$ of PBS and incubated in $500 \mu \mathrm{l}$ of PBS containing $50 \mu \mathrm{g} / \mathrm{ml}$ of propidium iodide and $50 \mu \mathrm{l}$ of $1 \mathrm{mg} / \mathrm{ml}$ of RNase $\mathrm{A}$ in the dark for $30 \mathrm{~min}$ at room temperature. Cell cycle was analyzed by flow cytometry.

\section{Preparation of cytosolic and nuclear extracts}

MCF-10A and MCF-7 cells were collected and suspended in 100 $\mu$ l of hypotonic buffer A [10 mM HEPES ( $\mathrm{pH} 7.8), 1.5 \mathrm{mM} \mathrm{MgCl}_{2}$, $10 \mathrm{mM} \mathrm{KCl}, 0.5 \mathrm{mM} \mathrm{DTT}, 0.2 \mathrm{mM}$ phenylmethanesulphonylfluoride (PMSF)] for 15 min on ice, and $1 \mu$ l of $10 \%$ Nonidet P40 solution was added for $5 \mathrm{~min}$. The mixture was centrifuged at $12,000 \times g$ for $5 \mathrm{~min}$. The supernatant containing cytosolic proteins was collected and stored at $-70^{\circ} \mathrm{C}$. The pellets were washed with hypotonic buffer and resuspended in hypertonic buffer $\mathrm{C}$ [20 $\mathrm{mM}$ HEPES (pH 7.8), 20\% glycerol, $420 \mathrm{mM} \mathrm{NaCl}, 1.5 \mathrm{mM}$ $\mathrm{MgCl}_{2}, 0.2 \mathrm{mM}$ EDTA, $0.5 \mathrm{mM}$ DTT, $0.2 \mathrm{mM}$ PMSF] for $1 \mathrm{~h}$ on ice and centrifuged at $12,000 \times g$ for $7 \mathrm{~min}$. The supernatant containing nuclear proteins was collected and stored at $-70^{\circ} \mathrm{C}$ after determination of protein concentrations. The protein concentration of the cytosolic and nuclear extracts was determined using the BCA protein assay kit (Pierce, USA).

\section{Protein extraction and Western blot analysis}

Cell extracts were prepared by suspending cells directly in the radioimmunoprecipitation assay (RIPA) buffer [20 mM Tris$\mathrm{HCl}$ (pH 7.5), $150 \mathrm{mM} \mathrm{NaCl}, 1 \mathrm{mM} \mathrm{Na}{ }_{2}$ EDTA, $1 \mathrm{mM}$ EGTA, $1 \%$ Triton $\mathrm{X}-100,2.5 \mathrm{mM}$ sodium pyrophosphate, $1 \mathrm{mM} \beta$ - 
glycerophosphate, $1 \mathrm{mM} \mathrm{Na}_{3} \mathrm{VO}_{4}, 1 \mu \mathrm{g} / \mathrm{ml}$ leuptin, $1 \mathrm{mM} \mathrm{PMSF}$ for $1 \mathrm{~h}$ on ice, followed by centrifugation for $15 \mathrm{~min}$ at $12000 \times \mathrm{g}$. Protein lysates $(15 \mu \mathrm{g})$ were electrophoresed by sodium dodecyl sulphate (SDS)-polyacrylamide gel electrophoresis (PAGE), and the separated proteins were transferred to a polyvinyl difluoride (PVDF) membrane (0.22 $\mu \mathrm{m}$ thickness; Gelman Laboratory, USA). To block the non-specific binding of proteins with primary antibodies, the blots were incubated in a 5\% non-fat dry milkPBST buffer [PBS containing $0.1 \%$ Tween-20] for $1 \mathrm{~h}$ at room temperature. The membranes were then incubated with the primary antibody suspended in 3\% non-fat milk PBST buffer overnight at $4^{\circ} \mathrm{C}$. This was followed by washing with $1 \times$ PBST and incubation using appropriate secondary antibody coupled to horseradish peroxidase. Proteins tagged with specific primary antibodies were visualized with an enhanced chemiluminescence detection kit (Amersham Pharmacia Biotech, UK).

Reverse transcriptase-polymerase chain reaction (RT-PCR) Total RNA was isolated from MCF10A and MCF7 cells using TRIzol reagent (Invitrogen). One microgram of total RNA was reverse transcribed with murine leukemia virus reverse transcriptase (Promega, USA) at $42^{\circ} \mathrm{C}$ for $50 \mathrm{~min}$ and at $72^{\circ} \mathrm{C}$ for $15 \mathrm{~min}$. Reverse transcriptase-PCR was performed following standard procedures. PCR conditions for $\mathrm{HO}^{-1}$ and the house keeping gene, glyceraldehydes-3-phosphate dehydrogenase (GAPDH), were as follows: 30 cycles of $95^{\circ} \mathrm{C}$ for $30 \mathrm{~s} ; 55^{\circ} \mathrm{C}$ for $30 \mathrm{~s}$ and $72^{\circ} \mathrm{C}$ for $1 \mathrm{~min}$. The primers used for the reverse transcription-PCR are as follows (forward and reverse, respectively): HO-1; 5'-CAGGCAGAGAATGCTGAGTTC-3' and 5'-GATGTTGAGCAGGAACGCAGT-3' and GAPDH; 5'-TGAAGGTCGGTGTCAACGGATTTGGC-3' and 5'-CATGTAGGCCATGAGGTCCACCAC-3'. Amplification products were analyzed on $2 \%$ agarose gel electrophoresis, stained with ethidium bromide and photographed under ultraviolet light.

\section{Transfection}

siRNA oligonucleotides targeting $\mathrm{HO}-1$ and $\mathrm{Nrf2}$ were purchased from Santa Cruz Biotechnology. Cells $\left(3 \times 10^{5} / 60-\mathrm{mm}\right.$ dish) were transfected with $25 \mathrm{nM}$ of specific or scrambled siRNA oligonucleotides using Lipofectamine RNAiMAX according to the manufacturer's instructions (Invitrogen).

\section{Measurement of glutathione levels}

Cell pellets were resuspended in 5\% metaphosphoric acid (Sigma-Aldrich), and supernatants were collected to determine total glutathione and oxidized glutathione (GSSG) concentrations using the EnzyChrom GSH/GSSG assay kit according to the manufacturer's protocol (Bioassay systems, USA). 5,5'Dithiobis (2-nitrobenzoic acid) (DNTB) reacts with reduced GSH and subsequently forms a yellow product. The change in absorbance was monitored at $410 \mathrm{~nm}$ for $10 \mathrm{~min}$, and the reduced glutathione (GSH) concentration was obtained by subtracting the oxidized from the total concentration.

\section{Measurement of intracellular accumulation of reactive oxygen species}

The intracellular accumulation of hydrogen peroxide was assessed by flow cytometry using the fluorescent probe $2^{\prime}, 7^{\prime}$ dichlorofluorescein diacetate (DCF-DA) (Molecular Probe, USA). Cells were washed twice with Hanks balanced salt solution (HBSS; Cellgro, USA) and incubated with $10 \mu \mathrm{M}$ of DCFDA in humidified $5 \% \mathrm{CO}_{2}$ at $37^{\circ} \mathrm{C}$. After $30 \mathrm{~min}$, cells were washed twice with HBSS solution, suspended in complete media and analyzed by flow cytometry.
In vitro pull-down assay

Cell lysates $(500 \mathrm{mg})$ were incubated with either Sepharose 4B or piperlongumine-Sepharose $4 \mathrm{~B}$ beads in reaction buffer [50 $\mathrm{mM}$ Tris (pH 7.5), $5 \mathrm{mM}$ EDTA, $150 \mathrm{mM} \mathrm{NaCl}, 1 \mathrm{mM}$ DTT, $0.01 \% \mathrm{NP}-40$, and $2 \mathrm{mg} / \mathrm{ml}$ bovine serum albumin). After incubation with gentle rocking overnight at $4^{\circ} \mathrm{C}$, the beads were washed with buffer [50 mM Tris (pH 7.5), $5 \mathrm{mM}$ EDTA, $150 \mathrm{mM}$ $\mathrm{NaCl}, 1 \mathrm{mM}$ DTT and $0.01 \% \mathrm{NP}-40$ ], and the interaction between piperlongumine and Keap1 was visualized by Western blot analysis.

\section{Statistical analysis}

Values were expressed as the mean \pm S.D. of three independent experiments. Statistical significance was determined by Student's $t$-test and the $p$-value of less than 0.05 was considered to be statistically significant.

\section{RESULTS}

Piperlongumine selectively kills human breast cancer MCF-7 cells but not human MCF-10A breast epithelial cells To determine the effects of piperlongumine on the viability of normal and cancer cells, human MCF-10A breast epithelial cells and breast cancer MCF-7 cells were stimulated with varying concentrations of piperlongumine for $24 \mathrm{~h}$. As shown in Fig. 1A, piperlongumine increased MCF-7 cell death in a concentrationdependent manner, but it barely affected the viability of MCF-10A cells. Maximum selective killing effects of piperlongumine on cancer cells were observed at $5 \mu \mathrm{M}$. Next, we evaluated apoptosis in MCF-10A and MCF-7 cells after piperlongumine $(5 \mu \mathrm{M})$ treatment. Through annexin $\mathrm{V}$ and $\mathrm{PI}$ double staining, it was revealed that piperlongumine-treated MCF-7 cells underwent apoptosis whereas MCF-10A cells were less sensitive to piperlongumine-induced apoptosis. The apoptosis indices were $21.9 \%$ in MCF-7 cells and $6.7 \%$ in MCF-10A cells, respectively, after treatment of piperlongumine for $36 \mathrm{~h}$ (Fig. 1B). Moreover, piperlongumine significantly increased the proportion of MCF-7 cells in the sub-G1 stage, but not in MCF-10A cells (Fig. 1C). We then examined PARP cleavage, a hallmark of apoptosis. Following piperlongumine treatment, cleaved PARP levels increased in time- (Fig. 1D) and dose-dependent (Fig. 1E) manners in MCF-7 cells, but not in MCF-10A cells. These data clearly show that piperlongumine has a cancer cell-selective killing effect.

Piperlongumine-induced HO-1 expression plays a different role in MCF-10A and MCF-7 cells, thereby mediating the selective effect on cancer cell apoptosis

To elucidate the mechanism underlying the selective killing effect of piperlongumine on MCF-7 cells, we examined the level of cytoprotective proteins including $\mathrm{HO}-1$ and Nrf2 after piperlongumine treatment. In contrast to our expectation, although piperlongumine selectively induced apoptosis in MCF-7 cells, HO-1 and Nrf2 expression levels were upregulated by piperlongumine in both MCF-10A and MCF-7 cells (Figs. 2A and $2 \mathrm{~B}$ ). Piperlongumine upregulated the expression of $\mathrm{HO}-1$ and Nrf2 in MCF-10A cells at an earlier time compared to MCF7 cells. In parallel with the elevated protein level of $\mathrm{HO}-1$, the expression of its mRNA transcript was also increased in both MCF-10A and MCF-7 cells after piperlongumine treatment (Fig. $2 \mathrm{C}$ ). To investigate whether $\mathrm{HO}-1$ plays a role in determining the differential effects of piperlongumine, we utilized siRNA against $\mathrm{HO}-1$. As shown in Fig. 2D, piperlongumine increased the level of cleaved PARP in MCF-10A cells transfected with $\mathrm{HO}-1$ siRNA, indicating that HO-1 protects MCF-10A cells from 

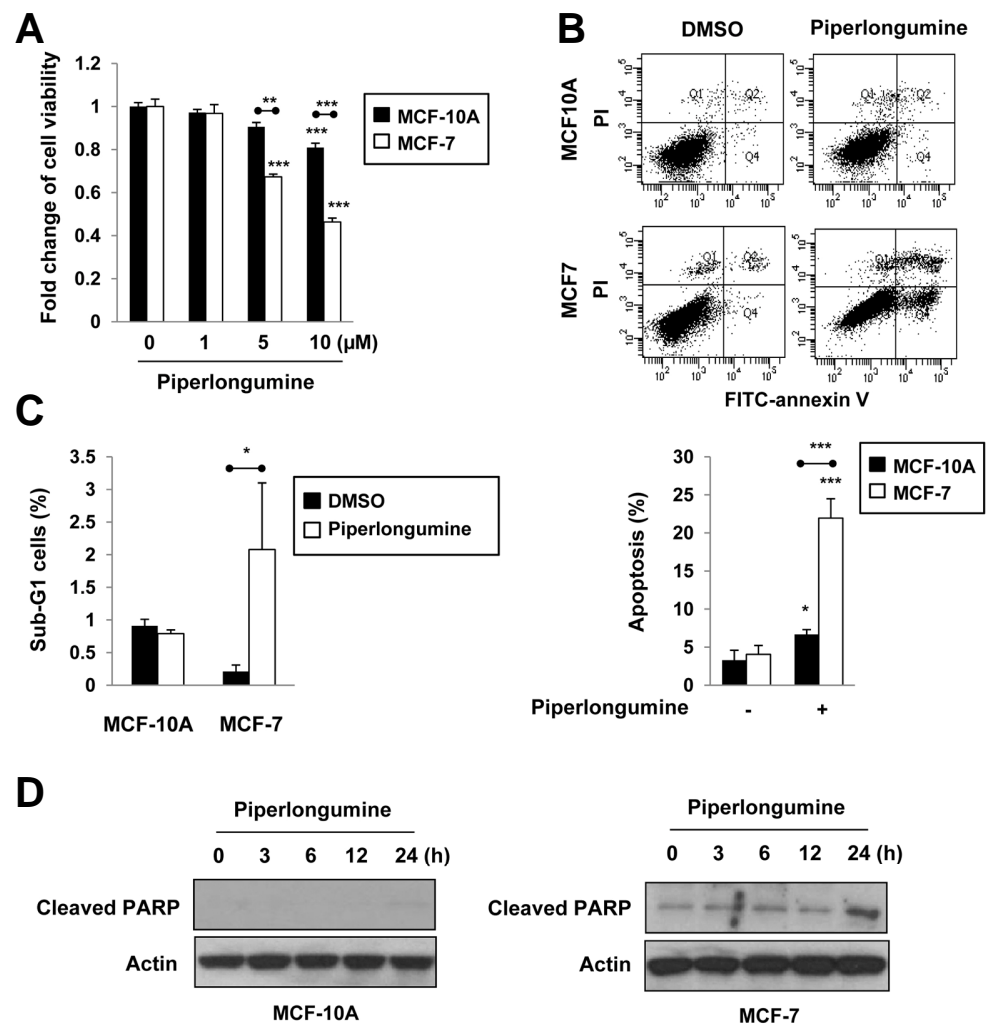

E

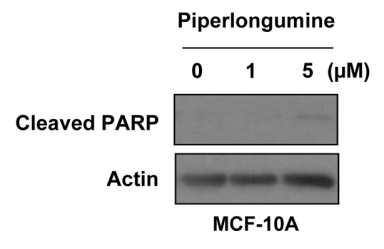

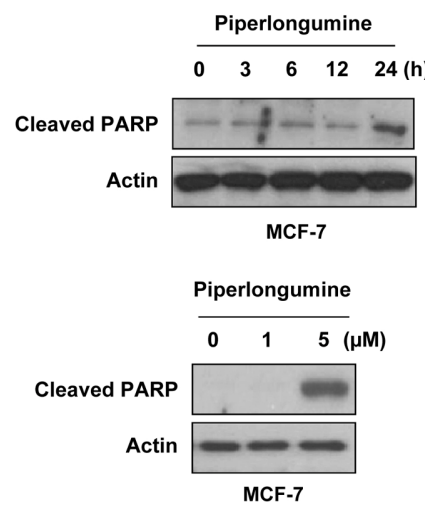

Fig. 1. Piperlongumine induces apoptosis in human breast cancer MCF-7 cells relative to human MCF-10A breast epithelial cells. (A) MCF-10A and MCF-7 cells were treated with $0,1,5$ or $10 \mu \mathrm{M}$ of piperlongumine for $24 \mathrm{~h}$. Cell viability was evaluated by the MTT assay. (B, C) Cells were treated with $5 \mu \mathrm{M}$ of piperlongumine for $36 \mathrm{~h}$. Quantification of apoptosis was determined by flow cytometry (B). The proportion of the cells at the sub-G1 phase was also assessed by flow cytometry analysis as described in the Materials and Methods section (C). Means \pm S.D. $(n=3),{ }^{*} p<0.05, "{ }^{* *} p<0.01,{ }^{* * *} p<$ 0.001. (D, E) MCF-10A and MCF-7 cells were treated with $5 \mu \mathrm{M}$ of piperlongumine for the indicated time periods (D) and 0,1 or $5 \mu \mathrm{M}$ of piperlongumine for $24 \mathrm{~h}(\mathrm{E})$. Total protein isolated from cell lysates was subjected to immunoblot analysis for the measurement of cleaved PARP. Actin was used as an equal loading control for normalization. piperlongumine-induced apoptosis. In contrast to MCF-10A cells, MCF-7 cells became less sensitive to piperlongumine-induced apoptosis when $\mathrm{HO}-1$ was silenced (Figs. 2D and 2E), suggesting that piperlongumine triggers apoptosis of MCF-7 cells via $\mathrm{HO}$ 1 induction. The different role of $\mathrm{HO}-1$ in piperlongumine-treated MCF-10A and MCF-7 cells was also confirmed by ZnPP (a pharmacological inhibitor of HO-1 activity) treatment. Similar to HO-1 siRNA, ZnPP abrogated piperlongumine-induced apoptosis in MCF-7 cells, but stimulated apoptosis of MCF-10A cells in response to piperlongumine (Fig. 2F). These findings suggest that $\mathrm{HO}-1$ is the key protein involved in determining the selective effect of piperlongumine on cancer cell apoptosis. $\mathrm{HO}-1$ protects MCF-10A cells from piperlongumine-induced apoptosis while amplifying the cytotoxicity of piperlongumine in MCF-7 cells.

\section{Piperlongumine-induced Nif2 activation and HO-1 expression do not rely on ROS generation}

Because Nrf2 is one of major transcription factors involved in $\mathrm{HO}-$ 1 regulation (Itoh et al., 1999), we examined whether piperlongumine could activate Nrf2 signaling. Following piperlongumine treatment, Nrf2 was translocated into the nucleus in both MCF$10 \mathrm{~A}$ and MCF-7 cells (Fig. 3A). To determine whether HO-1 upregulation by piperlongumine was mediated via Nrf2 activation, cells were transiently transfected with siRNA against Nrf2. As shown in Fig 3B, piperlongumine failed to upregulate $\mathrm{HO}-1$ expression in Nrf2 knockdown cells, indicating that activation of Nrf2 signaling is important for piperlongumine-induced $\mathrm{HO}-1$ expression. It has been reported that piperlongumine modulates redox signaling, thereby increasing ROS production in cancer cells but not in normal cells (Raj et al., 2011). In the present study, we also observed that piperlongumine treatment lowered total and GSH levels, while increasing the level of GSSG in MCF-7 cells. However, there were no significant changes in the total GSH level and the GSH/GSSG ratio in piperlongumine-treated MCF-10A cells compared with those in DMSO-treated cells (Fig. 4A). Besides GSH depletion, piperlongumine treatment led to accumulation of intracellular ROS in MCF-7 cells, but this ROS generation was abrogated by pretreatment of NAC or trolox (Fig. 4B). Next, we examined the possible involvement of ROS in piperlongumine-induced Nrf2 activation and $\mathrm{HO}-1$ expression. As shown in Figs. 4C and 4D, piperlongumine-induced nuclear translocation of Nrf2 and upregulation of $\mathrm{HO}-1$ expression were markedly suppressed by NAC treatment in MCF-7 cells. Although piperlongumine did not increase ROS levels in MCF$10 \mathrm{~A}$ cells, NAC also abolished piperlongumine-induced Nrf2 activation and HO-1 overexpression in MCF-10A cells, indicating that NAC, which can act as a thiol reducing agent, directly inhibited piperlongumine-mediated stimulation of the $\mathrm{Nrf} / \mathrm{HO}-1$ 
A

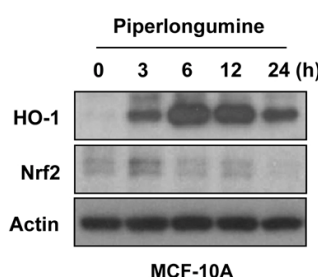

B

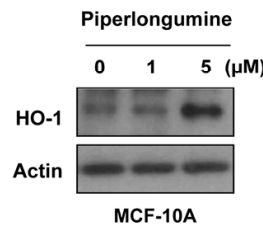

C

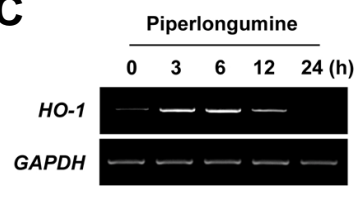

MCF-10A

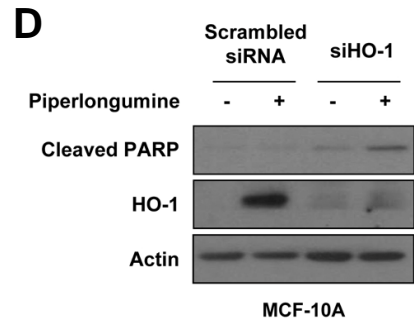

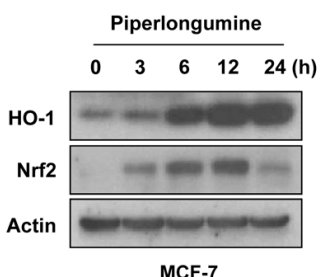
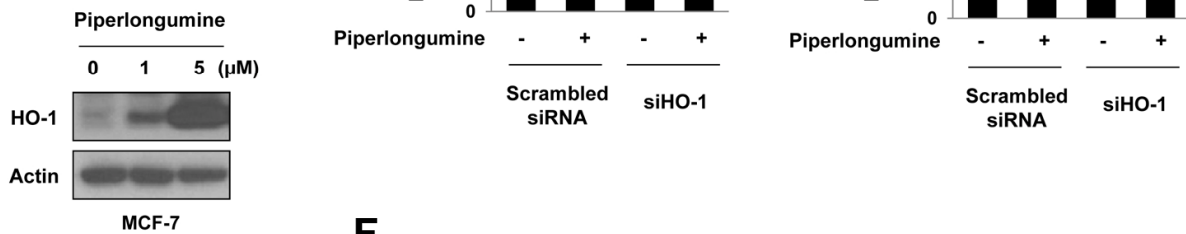

$\boldsymbol{F}$
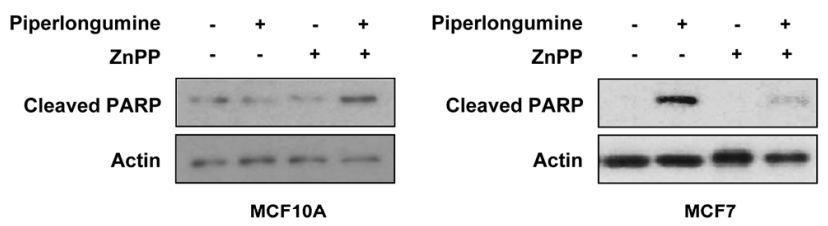

Fig. 2. HO-1 mediates the selective effect of piperlongumine on cancer cell apoptosis. (A-C) MCF-10A and MCF-7 cells were treated with 5 $\mu \mathrm{M}$ of piperlongumine for the indicated time periods $(\mathrm{A}, \mathrm{C})$ and 0,1 or $5 \mu \mathrm{M}$ of piperlongumine for $24 \mathrm{~h}(\mathrm{~B})$. (A, B) Total protein isolated from cell lysates was subjected to immunoblot analysis for the measurement of HO-1 and Nrf2. Actin was used as an equal loading control for normalization. (C) The expression of HO-1 mRNA was determined by semi-quantitative RT-PCR. The level of GAPDH mRNA was used as an internal control. (D, E) Cells were transfected with scrambled or $\mathrm{HO}-1$ siRNA for $24 \mathrm{~h}$, and then exposed to piperlongumine for additional $24 \mathrm{~h}$. The protein levels of cleaved PAPR, HO-1 and actin were determined by Western blot analysis (D). Cell viability was evaluated by the MTT assay (E). Means \pm S.D. $(n=3), " p<0.01, " * p<0.001$. (F) MCF-10A and MCF-7 cells were treated with piperlongumine in the absence or presence of $\mathrm{ZnPP}$ for $24 \mathrm{~h}$. The protein levels of cleaved PAPR, HO-1 and actin were determined by Western blot analysis.

pathway, rather than acting as a ROS scavenger. To confirm the role of ROS in piperlongumine-mediated effects, cells were treated with piperlongumine in the absence or presence of trolox, which also has ROS scavenging activity. Trolox failed to reverse the effect of piperlongumine on Nrf2 activation and $\mathrm{HO}$ 1 expression both in MCF-10A and MCF-7 cells (Figs. 4E and $4 \mathrm{~F})$. Moreover, the selective killing effect of piperlongumine on MCF-7 cells was not inhibited by trolox treatment (Fig. 4F). These results suggest that piperlongumine-induced Nrf2 activation, HO-1 expression and cancer cell death do not rely on ROS generation.

Piperlongumine induces Nrf2 activation and HO-1 expression through modification of Keap1 cysteine residues

It is well established that Keap1 is bound to Nrf2 under physiological conditions and inhibits the nuclear translocation of Nrf2. Oxidative stress or electrophiles can cause oxidation or cova- lent modification of cysteine residues present in Keap1, thereby activating Nrf2 signaling (Kim et al., 2014). Considering that piperlongumine contains the $\alpha, \beta$-unsaturated carbonyl moiety (Fig. 5A), we expected that piperlongumine-induced Nrf2 activation and $\mathrm{HO}-1$ expression is mediated by thiol modification of cysteine residues present in Keap1. In support with our hypothesis, the effects of piperlongumine on the nuclear translocation of Nrf2 and the expression of HO-1 were abrogated when cells were pre-treated with DTT, a thiol reducing agent (Figs. 5B and $5 C)$. To investigate whether piperlongumine induces thiol modification through direct binding to Keap1, pull-down assays were performed using piperlongumine-conjugated Sepharose 4B beads with MCF-10A and MCF-7 cell lysates. As shown in Fig. $5 \mathrm{D}$, piperlongumine directly bound to Keap1 both in MCF-10A and MCF-7 cells. These data imply that piperlongumine induces Nrf2 activation and HO-1 expression through modification of Keap1 cysteine residues. 
HO-1 Mediates the Selective Killing Effect of Piperlongumine

Ha-Na Lee et al.

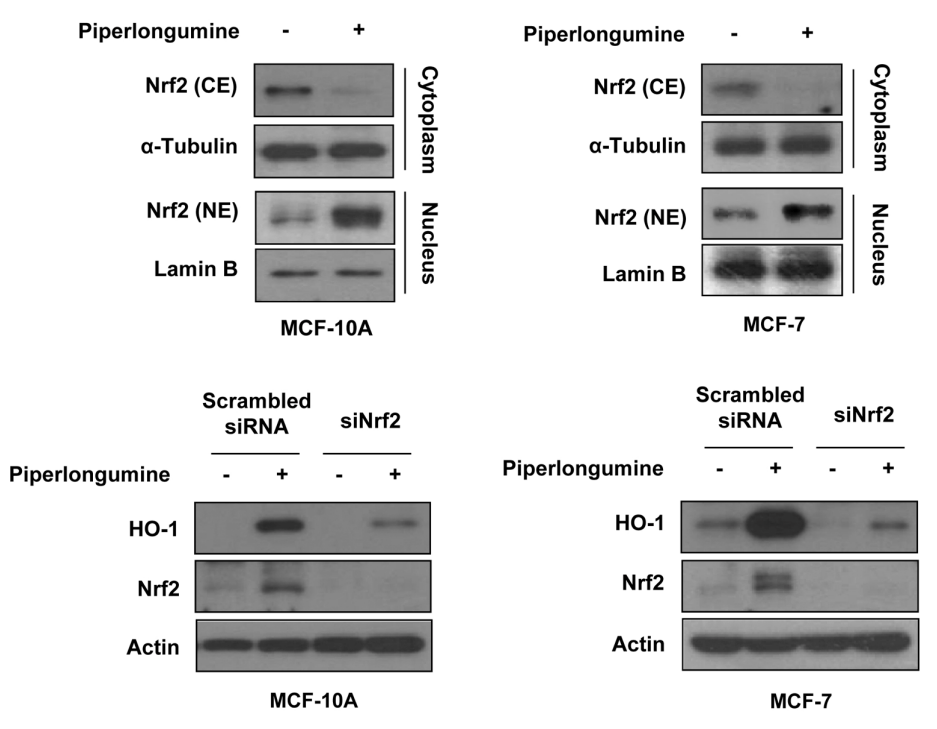

Fig. 3. Piperlongumine upregulates $\mathrm{HO}-1$ expression through Nrf2 activation. (A) Cytosolic and nuclear extracts were prepared from MCF-10A and MCF-7 cells treated with or without piperlongumine $(5 \mu \mathrm{M})$ for $3 \mathrm{~h}$ (MCF-10A) or $12 \mathrm{~h}$ (MCF-7). The protein levels of Nrf2 were measured by Western blot analysis. $\alpha$-Tubulin and Lamin B1 was used as an equal loading control for normalization. (B) Cells were transfected with scrambled or Nrf2 siRNA for $24 \mathrm{~h}$, and then treated with piperlongumine for additional $3 \mathrm{~h}$ (MCF-10A) or $12 \mathrm{~h}$ (MCF-7). The protein levels of HO-1, Nrf2 and actin were determined by Western blot analysis.

A

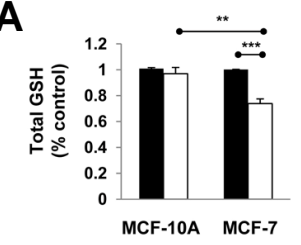

c

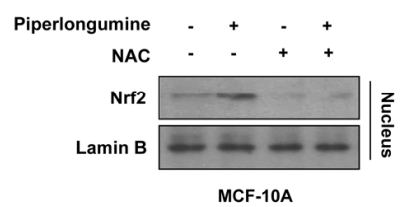

D

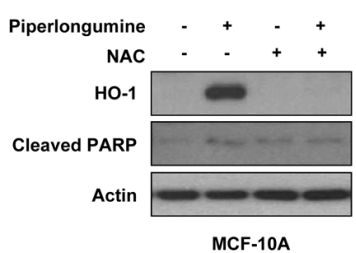

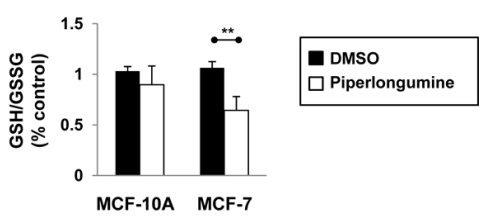

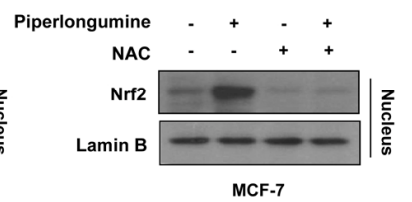

MCF-7

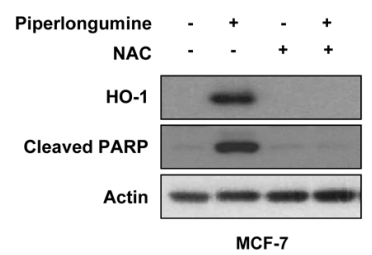

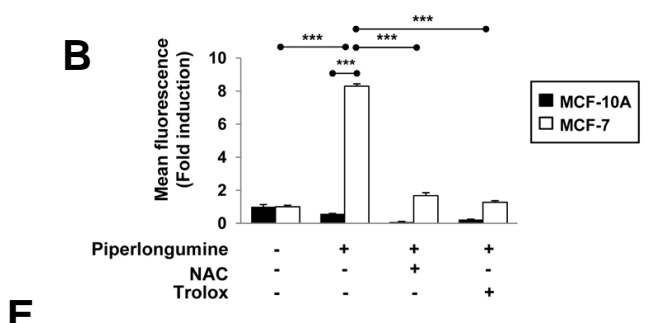

Piperlongumine - + - +

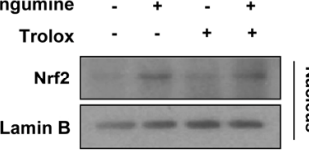

MCF-10A

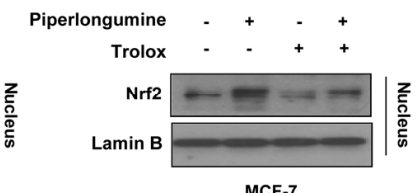

$\boldsymbol{F}$

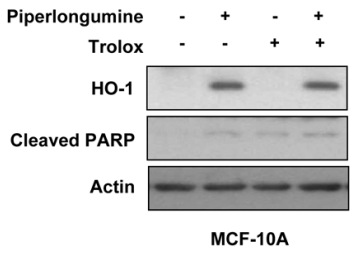

Fig. 4. Piperlongumine-induced Nrf2 activation and HO-1 expression is not dependent on ROS generation. (A) Reduced GSH and GSSG levels were determined after cells were treated with piperlongumine for $3 \mathrm{~h}$. (B) MCF-10A and MCF-7 cells were stimulated with piperlongumine in the absence or presence of either NAC or trolox for $3 \mathrm{~h}$, and the intracellular ROS levels were measured by flow cytometry as described in the Materials and methods section. Means \pm S.D. $(n=3)$, ${ }^{\star *} p<0.01,{ }^{\star \star *} p<0.001$. (C, E) Cells were pretreated with either NAC (C) or trolox (E) for $2 \mathrm{~h}$, followed by piperlongumine treatment for $3 \mathrm{~h}$ (MCF-10A) or $12 \mathrm{~h}$ (MCF-7). Nuclear extracts were subjected to immunoblot analysis for the measurement of Nrf2. Lamin B was used as an equal loading control for normalization. (D, F) MCF-10A and MCF7 cells were pretreated with either NAC (D) or trolox (F) for $2 \mathrm{~h}$, followed by treatment of piperlongumine for $24 \mathrm{~h}$. Levels of HO-1, cleaved PARP and actin were measured by Western blot analysis.

\section{DISCUSSION}

Since conventional chemotherapy for breast cancer treatment faces serious challenges such as damage to normal cells, drug resistance and toxic side effects, a dietary phytochemical has been increasingly considered as an alternative due to its safety as well as its efficient therapeutic effect. To date, various phytochemicals have been found to exert anti-oxidant, antiinflammatory, anti-proliferative and pro-apoptotic effects, thereby being utilized as a source of anticancer drugs as well as 
$\boldsymbol{A}$<smiles>COc1cc(C=CC(=O)N2CCC=CC2=O)cc(OC)c1OC</smiles>

B

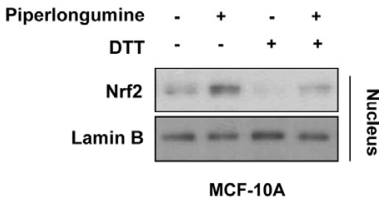

\section{C}

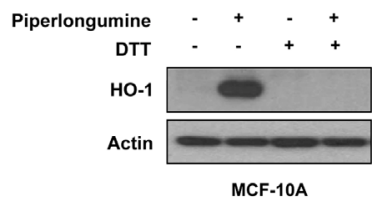

$D$

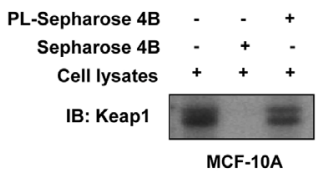

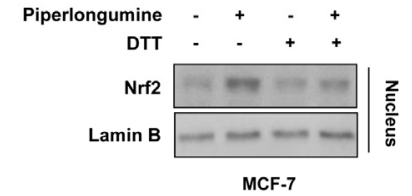
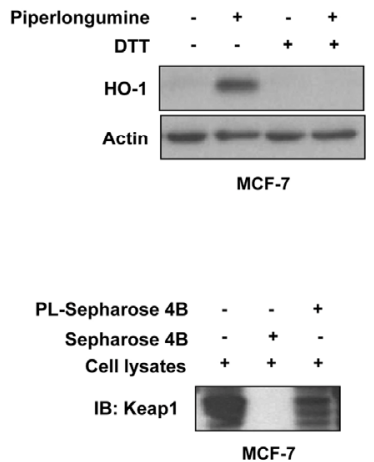

Fig. 5. Interaction of piperlongumine with cysteine residues within Keap1 activates Nrf2/HO-1 pathway. (A) The structure of piperlongumine. Electrophilic carbons containing $\alpha, \beta$-unsaturated carbonyl moiety are denoted by asterisks. (B) Cells were treated with $5 \mu \mathrm{M}$ of piperlongumine in the absence or presence of DTT for $3 \mathrm{~h}$ (MCF$10 \mathrm{~A})$ or $12 \mathrm{~h}$ (MCF-7). Nuclear extracts were subjected to immunoblot analysis for the measurement of Nrf2. Lamin B was used as an equal loading control for normalization. (C) MCF-10A and MCF-7 cells were exposed to piperlongumine for $24 \mathrm{~h}$. Levels of HO-1, cleaved PARP and actin were measured by Western blot analysis. (D) Cell lysates were incubated with piperlongumineconjugated Sepharose 4B beads (PL-Sepharose 4B) or Sepharose $4 \mathrm{~B}$ beads alone, and then the pulled-down Keap1 was detected by immunoblot analysis.

chemopreventive agents (Russo et al., 2010). Piperlongumine, a biologically active alkaloid/amide derived from the long pepper (Piper longum L.), has been widely used in Indian Ayurvedic medicine for thousands of years to treat bronchitis, asthma, respiratory infections, cholera, malaria, diarrhea, stomachache and tumors (Bezerra et al., 2012). Interestingly, the most recent finding implies a cancer cell-selective killing effect of piperlongumine (Raj et al., 2011). In the present study, we also found that piperlongumine selectively kills human breast cancer MCF-7 cells but not human MCF-10A breast epithelial cells, supporting the potential of piperlongumine as a promising therapeutic for breast cancer treatment.

As a consequence of malignant transformation, cancer cells become to have high levels of ROS compared to normal cells, and show a strong reliance on the ROS stress-response pathway. Accumulating data indicate that ROS plays a key role in the cancer cell-selective cytotoxicity of piperlongumine (Liu et al., 2013; Raj et al., 2011). Through direct binding to GSTP1
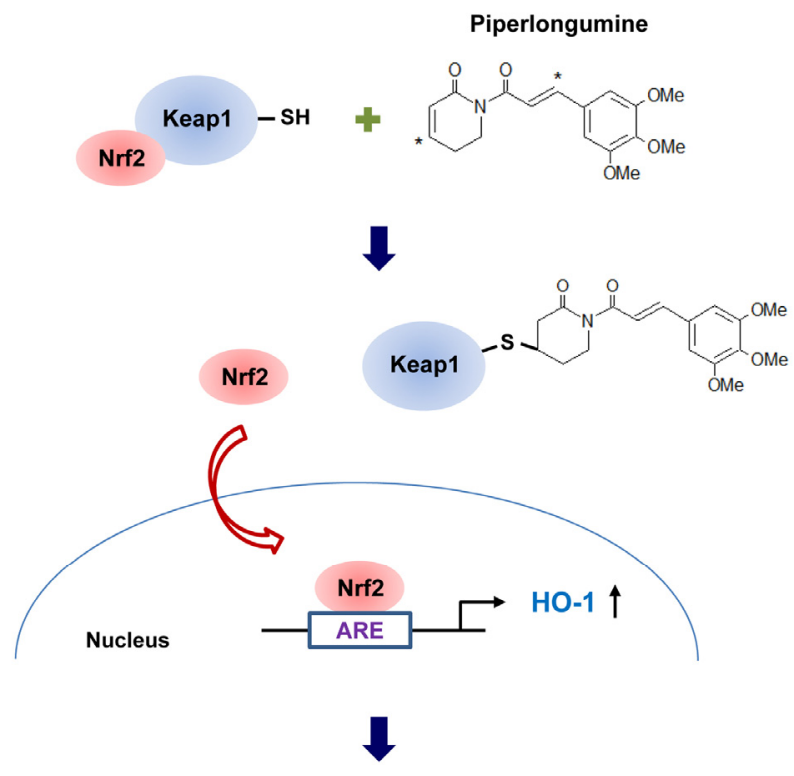

Selective killing of cancer cells

Fig. 6. The proposed mechanism underlying a cancer cell-selective killing effect of piperlongumine. Through direct binding, piperlongumine induces thiol modification of Keap1, thereby allowing nuclear translocation of Nrf2 and subsequent upregulation of HO-1 expression in normal and cancer cells. HO-1 determines the differential response of breast normal cells and cancer cells to piperlongumine, resulting in selective killing of cancer cells.

and CBR1 involved in oxidative stress balance, piperlongumine can selectively decrease the level of reduced GSH and increase the level of oxidized GSSG, leading to ROS accumulation and subsequent apoptosis in cancer cells (Raj et al., 2011). In agreement with this report, we observed piperlonguminemediated depletion of $\mathrm{GSH}$, a reduction in the GSH/GSSG ratio and accumulation of intracellular ROS in MCF-7 cells but not in MCF-10A cells. However, piperlongumine-induced ROS generation is unlikely to be involved in the pro-apoptotic effect of piperlongumine in cancer cells. Although piperlonguminemediated accumulation of ROS was completely blocked by pretreatment with NAC or trolox, both of which have the ability to quench ROS, piperlongumine-induced apoptosis was abrogated only in NAC-treated MCF7 cells but not in trolox-treated cells. Besides acting as a ROS scavenger, NAC is used as a precursor of GSH and a thiol reducing agent, thereby increasing the cell content of GSH and preventing oxidation of thiol groups (Dent et al., 1997). Based on this notion, we speculate that NAC-mediated suppression of apoptosis is mediated by inhibition of piperlongumine-induced thiol modification of proteins rather than preventing $\mathrm{ROS}$ generation.

Even though the role of HO-1 in cancer cells remains controversial, growing evidence supports the anti-tumor action of $\mathrm{HO}-1$. Hill et al. (2005) showed that upregulation of HO-1 expression by cobalt protoporphyrin or transfection with adenoviral vectors containing the $\mathrm{HO}^{-1}$ gene led to decreased proliferation of breast cancer cell. Moreover, HO-1 induction lowered the lymph node metastasis in human colorectal and oral carcinomas (Becker et al., 2007; Tsuji et al., 1999) while downregulation of HO-1 ex- 
pression stimulated malignant progression of hepatocellular carcinomas (Caballero et al., 2004). In agreement with these reports, we found that piperlongumine upregulated $\mathrm{HO}-1$ expression, and suppression of $\mathrm{HO}-1$ expression and activity abrogated the ability of piperlongumine to induce apoptosis in MCF-7 cells. To the best of our knowledge, this is the first report demonstrating that piperlongumine induces breast cancer cell apoptosis through the upregulation of $\mathrm{HO}-1$ expression. Notably, $\mathrm{HO}-1$ determines the differential response of MCF-10A and MCF-7 cells to piperlongumine. Piperlongumine increased the expression of HO-1 not only in MCF-7 cells, but MCF-10A cells. However, in contrast to MCF-7 cells, MCF-10A cells were sensitized to the cytotoxicity of piperlongumine when $\mathrm{HO}-1$ expression was silenced or its activity was blocked, indicative of the cytoprotective action of HO-1 in normal cells. Taken together, piperlongumineinduced HO-1 appears to act differently depending on the cell type, mediating the killing effect of piperlongumine in cancer cells and the protective effect in normal cells.

The transcriptional activation of $\mathrm{HO}-1$ is mainly regulated by the redox-sensitive transcription factor, Nrf2. Upon electrophilic or oxidative stress, Nrf2 dissociates from the Keap1-E3 ubiquitin ligase complex, translocates into the nucleus and initiates the transcription of $\mathrm{HO}-1$ via ARE binding sites (Itoh et al., 1997). In the present study, we have found that piperlongumine upregulates $\mathrm{HO}-1$ expression through $\mathrm{Nrf} 2$ activation in both MCF-10A and MCF-7 cells. The ability of piperlongumine to induce Nrf2-mediated $\mathrm{HO}-1$ expression was attenuated by pretreatment with NAC. However, it was assumed that NAC reverses piperlongumine-mediated Nrf2 activation and $\mathrm{HO}-1$ induction not by scavenging ROS because piperlongumine did not lead to an increasing ROS levels in MCF-10A, and trolox failed to suppress piperlongumine-induced Nrf2 activation and HO-1 expression in both MCF-10A and MCF-7 cells. These findings suggest that piperlongumine-induced Nrf2 activation and HO-1 expression do not rely on ROS generation.

It has been suggested that various chemopreventive agents activate Nrf2 signaling though cysteine modification-mediated Keap1 inactivation (Kobayashi et al., 2006). Through sitedirected mutagenesis of cysteine residues within Keap1, it has been revealed that Cys151, Cys273 and Cys288 are essential for regulating Nrf2 activation. These cysteines function as cellular redox sensors and can be subjected to oxidative or covalent modification (Kobayashi et al., 2009; Yamamoto et al., 2008; Zhang et al., 2004). Since piperlongumine possesses two electrophilic $\alpha, \beta$-unsaturated carbonyl groups capable of altering reactive cysteines, we expected that piperlongumine stimulates Nrf2 activation through direct cysteine modification. To examine the possibility of piperlongumine-mediated Nrf2 through direct Keap1 cysteine thiol modification, we utilized DTT, a strong reducing agent which can interfere with cysteine modification by electrophiles. In the presence of DTT, piperlongumine failed to upregulate Nrf2 activation and HO-1 expression in MCF-10A and MCF-7 cells, indicating that DTT keeps Keap1 thiol groups in a reduced form, thereby hampering interaction between piperlongumine and critical Keap1 cysteine residues. Moreover, our study clearly showed that piperlongumine directly bound to Keap1 as determined by the pull-down assays.

In conclusion, the results from our present study demonstrate a novel mechanism underlying a cancer cell-selective killing effect of piperlongumine (Fig. 6). We suggest that $\mathrm{HO}-1$ is a key factor determining the differential response of breast normal cells and cancer cells to piperlongumine, and the thiol modification of Keap1 is responsible for piperlongumine-induced activation of $\mathrm{Nr} 2$ signaling and $\mathrm{HO}-1$ expression.

\section{ACKNOWLEDGMENT}

This research has been supported by grants from the Radiation Bio-Resource Research Program of the Korea Institute of Radiological and Medical Sciences (No. 740802) funded by the Ministry of Education, Science and Technology in the Republic of Korea.

\section{REFERENCES}

Alam, J., Stewart, D., Touchard, C., Boinapally, S., Choi, A.M., and Cook, J.L. (1999). Nrf2, a Cap'n'Collar transcription factor, regulates induction of the heme oxygenase-1 gene. J. Biol.Chem. 274, 26071-26078.

Bae, J., Lee, D., Kim, Y.K., Gil, M., Lee, J.Y., and Lee, K.J. (2013). Berberine protects 6-hydroxydopamine-induced human dopaminergic neuronal cell death through the induction of heme oxygenase-1. Mol. Cells 35, 151-157.

Bauer, M., and Bauer, I. (2002). Heme oxygenase-1: Redox regulation and role in the hepatic response to oxidative stress. Antioxid. Redox Signal. 4, 749-758.

Becker, J.C., Fukui, H., Imai, Y., Sekikawa, A., Kimura, T., Yamagishi, H., Yoshitake, N., Pohle, T., Domschke, W., and Fujimori, T. (2007). Colonic expression of heme oxygenase-1 is associated with a better long-term survival in patients with colorectal cancer. Scand. J. Gastroenterol. 42, 852-858.

Bezerra, D.P., Pessoa, C., de Moraes, M.O., Saker-Neto, N., Silveira, E.R., and Costa-Lotufo, L.V. (2012). Overview of the therapeutic potential of piplartine (piperlongumine). Eur. J. Pharm. Sci. 48, 453-463.

Caballero, F., Meiss, R., Gimenez, A., Batlle, A., and Vazquez, E. (2004). Immunohistochemical analysis of heme oxygenase-1 in preneoplastic and neoplastic lesions during chemical hepatocarcinogenesis. Int. J. Exp. Pathol. 85, 213-221.

Cornblatt, B.S., Ye, L.X., Dinkova-Kostova, A.T., Erb, M., Fahey, J.W., Singh, N.K., Chen, M.S.A., Stierer, T., Garrett-Mayer, E., Argani, P., et al. (2007). Preclinical and clinical evaluation of sulforaphane for chemoprevention in the breast. Carcinogenesis 28, 1485-1490.

Dent, G., Rabe, K.F., and Magnussen, H. (1997). Augmentation of human neutrophil and alveolar macrophage LTB4 production by $\mathrm{N}$-acetylcysteine: role of hydrogen peroxide. Br. J. Pharmacol. 122, 758-764.

Ewing, P., Wilke, A., Eissner, G., Holler, E., Andreesen, R., and Gerbitz, A. (2005). Expression of heme oxygenase-1 protects endothelial cells from irradiation-induced apoptosis. Endothelium 12, 113-119.

Hill, M., Pereira, V., Chauveau, C., Zagani, R., Remy, S., Tesson, L., Mazal, D., Ubillos, L., Brion, R., Ashgar, K., et al. (2005). Heme oxygenase-1 inhibits rat and human breast cancer cell proliferation: mutual cross inhibition with indoleamine 2,3-dioxygenase. FASEB J. 19, 1957-1968

Itoh, K., Chiba, T., Takahashi, S., Ishii, T., Igarashi, K., Katoh, Y., Oyake, T., Hayashi, N., Satoh, K., Hatayama, I., et al. (1997). An Nif2/small Maf heterodimer mediates the induction of phase II detoxifying enzyme genes through antioxidant response elements. Biochem. Biophys. Res. Commun. 236, 313-322.

Itoh, K., Wakabayashi, N., Katoh, Y., Ishii, T., Igarashi, K., Engel, J.D., and Yamamoto, M. (1999). Keap1 represses nuclear activation of antioxidant responsive elements by Nrf2 through binding to the amino-terminal Neh2 domain. Genes Dev. 13, 7686.

Kensler, T.W., Wakabayashi, N., and Biswal, S. (2007). Cell survival responses to environmental stresses via the Keap1Nrf2-ARE pathway. Annu. Rev. Pharmacol. Toxicol. 47, 89-116.

Keum, Y.S., Han, Y.H., Liew, C., Kim, J.H., Xu, C.J., Yuan, X.L. Shakarjian, M.P., Chong, S.H., and Kong, A.N. (2006). Induction of heme oxygenase-1 (HO-1) and $\mathrm{NAD}[\mathrm{P}] \mathrm{H}$ : Quinone oxidoreductase 1 (NQO1) by a phenolic antioxidant, butylated hydroxyanisole (BHA) and its metabolite, tertbutylhydroquinone (tBHQ) in primary-cultured human and rat hepatocytes. Pharm. Res. 23, 2586-2594.

Kim, H.J., So, H.S., Lee, J.H., Lee, J.H., Park, C., Park, S.Y., Kim, Y.H., Youn, M.J., Kim, S.J., Chung, S.Y., et al. (2006). Heme oxygenase-1 attenuates the cisplatin-induced apoptosis of 
auditory cells via down-regulation of reactive oxygen species generation. Free Radic. Biol. Med. 40, 1810-1819.

Kim, S.H., Lee, I.C., Baek, H.S., Shin, I.S., Moon, C., Bae, C.S. Kim, S.H., Kim, J.C., and Kim, H.C. (2014). Mechanism for the protective effect of diallyl disulfide against cyclophosphamide acute urotoxicity in rats. Food Chem. Toxicol. 64, 110-118.

Kobayashi, A., Kang, M.I., Watai, Y., Tong, K.I., Shibata, T., Uchida, K., and Yamamoto, M. (2006). Oxidative and electrophilic stresses activate Nrf2 through inhibition of ubiquitination activity of Keap1. Mol. Cell. Biol. 26, 221-229.

Kobayashi, M., Li, L., Iwamoto, N., Nakajima-Takagi, Y., Kaneko, H., Nakayama, Y., Eguchi, M., Wada, Y., Kumagai, Y., and Yamamoto, M. (2009). The Antioxidant Defense System Keap1Nrf2 Comprises a Multiple Sensing Mechanism for Responding to a Wide Range of Chemical Compounds. Mol. Cell. Biol. 29, 493-502.

Lee, W.Y., Chen, Y.C., Shih, C.M., Lin, C.M., Cheng, C.H., Chen, K.C., and Lin, C.W. (2014). The induction of heme oxygenase-1 suppresses heat shock protein 90 and the proliferation of human breast cancer cells through its byproduct carbon monoxide. Toxicol. Appl. Pharmacol. 274, 55-62.

Lin, H.Y., Shen, S.C., and Chen, Y.C. (2005). Anti-inflammatory effect of heme oxygenase 1: Glycosylation and nitric oxide inhibition in macrophages. J. Cell Physiol. 202, 579-590.

Lin, H.Y., Shen, S.C., Lin, C.W., Yang, L.Y., and Chen, Y.C. (2007) Baicalein inhibition of hydrogen peroxide-induced apoptosis via ROS-dependent heme oxygenase 1 gene expression. Biochim. Biophys. Acta 1773, 1073-1086.

Lin, C.W., Shen, S.C., Hou, W.C., Yang, L.Y., and Chen, Y.C. (2008). Heme oxygenase-1 inhibits breast cancer invasion via suppressing the expression of matrix metalloproteinase-9. Mol. Cancer Ther. 7, 1195-1206.

Liu, J.M., Pan, F., Li, L., Liu, Q.R., Chen, Y., Xiong, X.X., Cheng, K.J., Bin Yu. S., Shi, Z., Yu, A.C.H., et al. (2013). Piperlongumine selectively kills glioblastoma multiforme cells via reactive oxygen species accumulation dependent JNK and p38 activation. Biochem. Biophys. Res. Commun. 437, 87-93.

Raj, L., Ide, T., Gurkar, A.U., Foley, M., Schenone, M., Li, X.,
Tolliday, N.J., Golub, T.R., Carr, S.A., Shamji, A.F., et al. (2011). Selective killing of cancer cells by a small molecule targeting the stress response to ROS. Nature 475, 231-234.

Rao, V.R., Muthenna, P., Shankaraiah, G., Akileshwari, C., Babu, K.H., Suresh, G., Babu, K.S., Chandra Kumar, R.S., Prasad, K.R., Yadav, P.A., et al. (2012). Synthesis and biological evaluation of new piplartine analogues as potent aldose reductase inhibitors (ARIs). Eur. J. Med. Chem. 57, 344-361.

Russo, M., Spagnuolo, C., Tedesco, I., and Russo, G.L. (2010). Phytochemicals in Cancer Prevention and Therapy: Truth or Dare? Toxins 2, 517-551.

Son, D.J., Kim, S.Y., Han, S.S., Kim, C.W., Kumar, S., Park, B.S., Lee, S.E., Yun, Y.P., Jo, H., and Park, Y.H. (2012) Piperlongumine inhibits atherosclerotic plaque formation and vascular smooth muscle cell proliferation by suppressing PDGF receptor signaling. Biochem. Biophys. Res. Commun. 427, 349354.

Tsuji, M.H., Yanagawa, T., Iwasa, S., Tabuchi, K., Onizawa, K., Bannai, S., Toyooka, H., and Yoshida, H. (1999). Heme oxygenase-1 expression in oral squamous cell carcinoma as involved in lymph node metastasis. Cancer lett. 138, 53-59.

Yamamoto, T., Suzuki, T., Kobayashi, A., Wakabayashi, J., Maher, J., Motohashi, H., and Yamamoto, M. (2008). Physiological significance of reactive cysteine residues of keap1 in determining Nrf2 activity. Mol. Cell. Biol. 28, 2758-2770.

Yang, Y.C., Lee, S.G., Lee, H.K., Kim, M.K., Lee, S.H., and Lee, H.S. (2002). A piperidine amide extracted from Piper longum $L$. fruit shows activity against Aedes aegypti mosquito larvae. J. Agric. Food Chem. 50, 3765-3767.

Zhang, D.D., Lo, S.C., Cross, J.V., Templeton, D.J., and Hannink M. (2004). Keap1 is a redox-regulated substrate adaptor protein for a Cul3-dependent ubiquitin ligase complex. Mol. Cell. Biol. 24, 10941-10953.

Zou, C., Zhang, H., Li, Q., Xiao, H., Yu, L., Ke, S., Zhou, L., Liu, W., Wang, W., Huang, H., et al. (2011). Heme oxygenase-1: a molecular brake on hepatocellular carcinoma cell migration. Carcinogenesis 32, 1840-1848. 